\title{
Colour gamut of pad-steam dyed cotton fabric from natural extracts of Rubia tinctorum and Rubia cordifolia
}

\begin{abstract}
Colour has always been important in fabrics. Colouration of textiles is a complicated procedure involving not only the material and dye but also many other auxiliaries and details concerning treatments and processes. In the present project, Rubia tinctorum (madder) and Rubia cordifolia (Turkey red) natural dyes were applied on pure cotton, light weight fabric by continuous dyeing process through heavy duty padding mangle machine, tenter frame and steamer. Various dyeing auxiliaries were employed to observe their impact on the dyeing of cotton. The role of mordants and other dyeing auxiliaries in creating variety of shades/colours from the same dye was obvious in case of both the natural dyes utilized in the current study. The madder root extracts yielded red to violet and orange shades. Application of Turkey red dye on cotton with five different metallic mordants produced range of shades from pastel violet to signal violet and red lilac. Other auxiliaries such as cross linking agents, cationizing agents, UV absorbers and some fixative type of finishes did not affect the shade of cotton samples.
\end{abstract}

Keywords: auxiliaries, cotton, Madder, mordents, shade, Turkey red
Volume 5 Issue 3 - 2019

\author{
Shahnaz Parveen Khattak,' Shabana Rafique,' \\ Tanveer Hussain, ${ }^{2}$ Faiza Inayat ${ }^{1}$ \\ 'College of Home Economics, University of Peshawar, Pakistan \\ ${ }^{2}$ National Textile University, Pakistan
}

Correspondence: Shahnaz Parveen, College of Home Economics, University of Peshawar, 25I20, Peshawar, Khyber Pakhtunkhwa, Pakistan, Email shahnazpkhattak@uop.edu.pk

Received: January 29, 2018 | Published: May 20, 2019

\section{Introduction}

Until the 20th century, natural dyes were widely used and traded. These were the only available source for colouring textiles. However, modern dyeing rarely uses them and their application is limited to craft dyers and specialist companies. The word "natural dye or colourant" is used for all such dyes which are obtained from sources such as vegetables, animals and minerals. These dyes are derived from such sources without any chemical processing. Most of the dyes used in textile dyeing are nowadays synthetic. It was in 1856, when new colouration techniques were introduced by William Henry Perkin with the discovery of so called basic dye (synthetic) from coal tar. ${ }^{2-4}$ These dyes were different in many respects from the already established natural colourants and were low cost, brilliant and independent of vagaries of agriculture. ${ }^{5}$ Under all these circumstances, natural dyes at the industrial level have nearly become obsolete but amongst craftsmen and hobbyists their popularity still exists.

Various shades are obtained from natural dyes. An extract of famous natural dye henna leaves yields from beautiful orange brown to shades of light yellowish- green. ${ }^{6}$ The extracts of madder root dye results in orange- red to shades of scarlet. Deep shades can also be produced in some kind of multiple dyeing. Large number of shades can be created by using mixtures of dyes such as yellow, red, blue and black. However, practically, this is not possible as various natural dyes require different auxiliaries (mordants) and procedures. Majority of the plants contain coloured material in one or more of their parts. They have natural potential for dye in their root, stem, leaves, flower, berries etc. These colourants have been used since ancient times for many purposes. However, all of these cannot be utilized in textile colouration due to required amount of colour and fastness properties.

Plants having dyes with high to moderate fastness properties and colour stability are used for textile dyeing. ${ }^{7}$ Conventional knowledge about natural dyes leads to the conviction that such colourants are environmentally friendlier as compared to their synthetic counterparts.
They have many advantages over synthetic dyes as they are generally considered as environmentally responsible. ${ }^{8}$ They exhibit better biodegradability and generally have higher compatibility with the environment. They contain natural colouring matter which are nonallergic, non-toxic, non-carcinogenic, non-hazardous to environment, warm, appealing and soothing to eyes colours, earth friendly and help in maintaining ecological balance..$^{910}$ In the present context of eco-friendliness and eco-preservation, their use in the colouration of textile and food has been revived. ${ }^{11}$

Most of natural dyes have no affinity for fibres and are usually applied with the help of mordants and other auxiliary agents. The process of mordanting has been known for many centuries. It is used to improve dye adsorption on the fibre and its wash fastness because the mordant has substantivity for both the colourant and the fibre and in bonding with the dye on the fibre, forming an insoluble precipitate. Bringing little variation in the dyeing procedures and using various products as mordants, the same dye can provide a wide range of totally different colours and shades. This vista is not possible in case of synthetic dyes. In addition, through a mix and match system a wide range of new colours and shades can be created. While some of the natural dyes show enhancement with ageing process, synthetic dyes show fading as the article becomes aged.

For commercialization of natural dyes for textile colouration, the use of modern application techniques need evaluation. ${ }^{12}$ Despite their inferior fastness properties and other characteristics such as low colour yield, limited availability and poor reproducibility, they are more acceptable to the people around the world who are environmentally conscious. ${ }^{13}$ These dyes are becoming more of interest because of environmental issues and concern over synthetic dyes. Research has initiated to find renewable resource of colouring matter from natural products. The current move for the interest in dyes from natural sources also expedited since many countries imposed stringent environmental standards in response to the allergic and standard reactions exposed by synthetic dyes. In addition to eco friendly textile colouration, some 
of the colouring matters from natural sources may possess medicinal properties also. These dyes have nowadays attracted the attention of the entire world due to their non-toxic and non-hazardous nature. ${ }^{14}$

The use of madder root has been found since ancient times for textile dyeing in many parts of the world. The Turkish red dye procedure was introduced in Europe in 17th and 18th Century. ${ }^{15}$ Cotton cloth was printed with natural dye extracts from madder, weld, and coreopsis with two mordanting agents, aluminium acetate, and aluminium potassium sulphate and the printed fabric was evaluated for fastness to light and washing.

\section{Extraction of natural colourants}

For achieving the desired dyeing characteristics, extraction of colourants from sources available in nature could prove one of the most important steps to treat textiles. ${ }^{16}$ It is also important to find and optimize the standard extraction process and their variables for particular natural sources which should be cost effective for the price of end product. Different methods for extracting dyes from these materials are aqueous extraction, enzyme assisted extraction and alcoholic or organic solvent extractions. Natural dyes are extracted from various parts of plants and majority of them have inherent antibacterial/anti-microbial properties. They therefore, also possess high medicinal values.

\section{Types of mordants and natural dyeing}

In the dyeing of cotton fabrics with natural colourants, metal mordants are essential as they influence the shade/colour produced from the process. The intensity of shade and relative colour strength (expressed as K/S values) available from natural dyeing depend on the type of mordant and the nature of the complex formed by mordant and dye. ${ }^{17,18}$ The most generally used mordant is supposed to be aluminium potassium sulphate. Other fairly common mordants are potassium dichromate, tin chloride, copper sulphate, iron sulphate or iron chloride. ${ }^{19}$ For successful commercial use of natural dyes, the suitable and standardized procedures of dyeing for particular fibredye (natural) system needs to be adopted. Therefore, to obtain novel shades with acceptable colour fastness and reproducibility, appropriate dyeing techniques/procedures have to be derived. The present study is aimed to examine the possibility of dyeing cotton fabric with various natural dyes using different dyeing auxiliaries (mordants, crosslinkers, UV absorbers, cationizing agents and some finishing agents) and to examine their impact on the shade of cotton fabric.

\section{Materials and method}

Samples of pure cotton fabric were dyed with two natural dyes using various mordants and other dyeing auxiliaries. All the recipes of these dyes were applied on the fabric by following the standard procedure of continuous dyeing process. The study was conducted in three phases: (i) extraction of dyes (ii) application of dyes and (iii) physical testing of dyed fabric samples. Plain woven, light-weight, $100 \%$ cotton fabric was obtained in unfinished form from a textile mill. Commercially applied, preparatory process of desizing, scouring and bleaching were carried out in laboratory scale to prepare for dyeing. In order to formulate various recipes of natural dyes for cotton fabric, a dye bath was prepared by using various auxiliaries such as mordants, cross linking agents, cationizing agents, UV absorbers and some fixative type of finishes..$^{20}$ Natural dyes utilized in this project were madder and Turkey red. Madder dye was extracted from the roots of its respective plant (Rubia tinctorum). Dry roots of this plant were obtained from Pride International, Karachi, Pakistan. Turkey red (Rubia cordifolia) was acquired from Sam vegetable colours, Muradabad, India in powder form (Table 1).

Table I Dyeing auxiliaries used in this study for the colouration of cotton ${ }^{22}$

\begin{tabular}{|c|c|c|c|}
\hline Commercial name & Function of auxiliary & Chemical constitution & Supplier \\
\hline Thermacol MP & Migration Inhibitor & $\begin{array}{l}\text { Aqueous solution of a poly-acrylic acid } \\
\text { derivatives }\end{array}$ & Huntsman, Textile Effects \\
\hline Albaflow Conti & Penetration Accelerant & $\begin{array}{l}\text { Preparation based on fatty alcohol } \\
\text { ethoxylate and alkyl phosphoric acid } \\
\text { Fixative, cationizing agent/ aqueous }\end{array}$ & Huntsman, Textile Effects \\
\hline Albafix WFF & Cationizing Agent & $\begin{array}{l}\text { preparation of a polymeric, quaternary } \\
\text { ammonium compound }\end{array}$ & Huntsman, Textile Effects \\
\hline Dicrylan & Finishing Agent & $\begin{array}{l}\text { Multipurpose polymer/polyurethane } \\
\text { emulsion }\end{array}$ & Huntsman, Textile Effects \\
\hline UV- SUN & UV Absorbers & $\begin{array}{l}\text { Reactive UV absorber based on an } \\
\text { oxalanilide }\end{array}$ & Huntsman, Textile Effects \\
\hline Rayosan C & & $\begin{array}{l}\text { Fibre-reactive UV absorbers/ heterocyclic } \\
\text { compound }\end{array}$ & Clariant International Ltd. \\
\hline Fixapret CPF & Crosslinking Agents & $\begin{array}{l}\text { Crosslinking agent/ methylolation product } \\
\text { based on glyoxalmonourein }\end{array}$ & BASF chemical company \\
\hline Fixapret F-ECO & & $\begin{array}{l}\text { Crosslinker/ modified } \\
\text { dimethyloldihydroxyethylene urea }\end{array}$ & BASF chemical company \\
\hline Knittex RCT & & $\begin{array}{l}\text { Crosslinking agent/modified dihydroxy } \\
\text { ethylene urea }\end{array}$ & Huntsman, Textile Effects \\
\hline
\end{tabular}

Laboratory grade, commercial compounds namely aluminium sulphate, copper sulphate, ferric chloride, potassium dichromate and hydrated potassium aluminium sulphate or $\mathrm{KAl}\left(\mathrm{SO}_{4}\right)_{2} \cdot 12 \mathrm{H}_{2} \mathrm{O}$ were employed as mordanting agents. Other products utilized in the dyeing bath included cross linking agents (Fixapret F-ECO, Fixapret CPF, Knittex RCT),, UV absorbers (UV-SUN, Rayosan C) and cationizing/ finishing agents (Albafix WFF, Dicrylan ). These were obtained from their companies of origin.

All the substances were applied both as pre-treatment as well as post-treatment. However, the control sample was dyed by a recipe having no mordant, cross linker, UV absorber or any finishing agent. 
Dyeing bath for such sample was prepared with only a natural dye and dyeing auxiliaries including wetting agent and migration inhibitor etc. Pre-mordanting and post-mordanting were carried out in the pretreatment and post-treatment processes respectively. In case of pretreatment technique, every specific recipe treatment was first applied on the sample with the use of padding mangle, followed by drying in the air and then steaming. Dye was afterward padded on the dried sample, followed by drying at $120^{\circ} \mathrm{C}$ and then steaming. In a posttreatment method, the order of procedure was dyeing the sample first and then padding it with a specific chemical treatment or recipe (such as mordanting, finishing, cationizing etc.). After dyeing, samples were graded and sorted according to various shades with the help of shade cards.

\section{Results and discussion}

\section{Colour shades of cotton fabrics dyed with natural madder dyes}

Data related to the shades produced by the two dyes utilized in this study is presented in Table 2 and Table 3 as well as Figure $1 \&$ Figure 2. Dyeing with madder resulted in reddish and purplish shade of dyed cotton samples (Table 2). The most reddish shade was offered by the sample obtained from the dye formulation having copper sulphate as post- mordant (Figure 1).

Table 2 Shades of cotton fabric obtained from dyeing with Madder root (Rubia tinctorum) dyes using various dyeing auxiliaries

\begin{tabular}{lll}
\hline Shade obtained & $\begin{array}{l}\text { Pre-treatment } \\
\text { with }\end{array}$ & $\begin{array}{l}\text { Post-treatment } \\
\text { with }\end{array}$ \\
\hline $\begin{array}{l}\text { Most reddish (brown } \\
\text { red) }\end{array}$ & -- & $\mathrm{CuSO}_{4}$ \\
Reddish (light red) & -- & Albafix \\
Reddish (pearl pink) & -- & $\mathrm{K}_{2} \mathrm{Cr}_{2} \mathrm{O}_{7}$ \\
Reddish (flame red) & $\mathrm{KAl}\left(\mathrm{SO}_{4}\right)_{2} \cdot 12 \mathrm{H}_{2} \mathrm{O}$ & -- \\
$\begin{array}{l}\text { Reddish- grey } \\
\text { Pinkish red (dark purl } \\
\text { pink) }\end{array}$ & -- & $\mathrm{FeCl}_{3}$ \\
$\begin{array}{l}\text { Orangish- red } \\
\text { Yellowish- orange }\end{array}$ & -- & -- \\
$\begin{array}{l}\text { Light reddish purple } \\
\text { Dull purple (pastel }\end{array}$ & $\begin{array}{l}\mathrm{Control} \mathrm{sample,} \\
\mathrm{K}_{2} \mathrm{Cr}_{2} \mathrm{O}_{7}\end{array}$ & -- \\
$\begin{array}{l}\text { violet) } \\
\text { Purple (signal violet) }\end{array}$ & $\mathrm{Al}_{2}\left(\mathrm{SO}_{4}\right)_{3}$ & -- \\
\hline
\end{tabular}

Similar shades were characterized by post- cationizing with Albafix. Orange-red tone was available from the treatment of postmordanting with $\mathrm{KAl}\left(\mathrm{SO}_{4}\right)_{2} \cdot 12 \mathrm{H}_{2} \mathrm{O}$. Pre- padding with Knittex produced yellow- orange shade and the dyeing was uneven. Dark, reddish- grey shade was introduced by the post-treatment of ferric chloride. All other recipes produced purplish or light reddish shades which were not very attractive.

\section{Colour shades of cotton fabrics dyed with natural Turkey red dye}

Natural extracts of Turkey red gave a range of purple shade with most of the dyeing recipes (Figure 2). Extremely beautiful, attractive, soft textured, smooth and evenly dyed sample in dark purple (signal violet) colour resulted from the dye formulation having pre-treatment of hydrated potassium aluminium sulfate $\left(\mathrm{KAl}\left(\mathrm{SO}_{4}\right)_{2} \cdot 12 \mathrm{H}_{2} \mathrm{O}\right)$. Beautiful shade of pure purple colour was displayed by pre- cationized cotton (Albafix WFF) sample dyed with Turkey red extracts. Slightly greater intensity of the same shade was exposed by the pre- treatments of UVSUN, Dicrylan and Fixapret CPF as well as the post- treatments of Albafix and control sample. Lighter shade of the purple was available from the dyeing recipes of the treatment with Fixapret F ECO, Knittex and post-mordanting of potassium dichromate. Cationization with Albafix (pre-padding) produced dull purple colour. These cross linkers might have reduced the $\mathrm{K} / \mathrm{S}$ value in light and medium shades.

Table 3 Shades of cotton fabric obtained from dyeing with Turkey red (Rubia cordifolia) using various dyeing auxiliaries

\begin{tabular}{|c|c|c|}
\hline Shade obtained & Pre-treatment & Post-treatment \\
\hline $\begin{array}{l}\text { Darkest purple (red } \\
\text { lilac) }\end{array}$ & $\mathrm{K}_{2} \mathrm{Cr}_{2} \mathrm{O}_{7}$ & -- \\
\hline Darker purple & $\mathrm{FeCl}_{3}$ & -- \\
\hline $\begin{array}{l}\text { Dark purple (pearl } \\
\text { violet) }\end{array}$ & $\begin{array}{l}\text { UV-SUN, Dicrylan, } \\
\text { Fixapret CPF, Fixapret } \\
\text { ECO, Knittex }\end{array}$ & Albafix, $\mathrm{K}_{2} \mathrm{Cr}_{2} \mathrm{O}_{7}$ \\
\hline $\begin{array}{l}\text { Dull purple (pastel } \\
\text { violet) }\end{array}$ & Albafix & -- \\
\hline $\begin{array}{l}\text { Reddish-purple (signal } \\
\text { violet) }\end{array}$ & $\begin{array}{l}\mathrm{KAl}\left(\mathrm{SO}_{4}\right)_{2} \cdot 12 \mathrm{H}_{2} \mathrm{O} \\
\mathrm{CuSO}_{4}\end{array}$ & $\mathrm{CuSO}_{4}$ \\
\hline $\begin{array}{l}\text { Reddish-purple (blue } \\
\text { lilac) }\end{array}$ & $\mathrm{Al}_{2}\left(\mathrm{SO}_{4}\right)_{3}$ & -- \\
\hline Maroonish & -- & $\mathrm{Al}_{2}\left(\mathrm{SO}_{4}\right)_{3}$ \\
\hline $\begin{array}{l}\text { Reddish-orange (salmon } \\
\text { pink) }\end{array}$ & -- & $\mathrm{KAl}\left(\mathrm{SO}_{4}\right)_{2} \cdot 12 \mathrm{H}_{2} \mathrm{O}$ \\
\hline
\end{tabular}

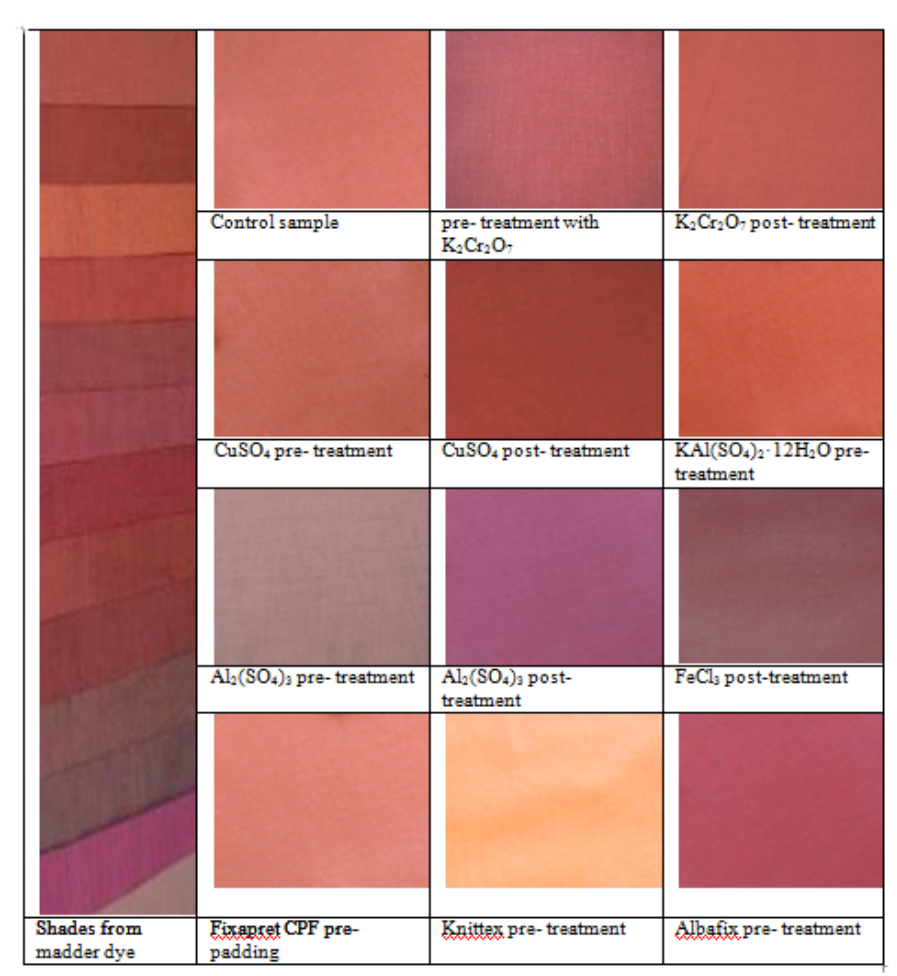

Figure I Colour shades of cotton samples dyed with natural extracts of madder under different conditions. 


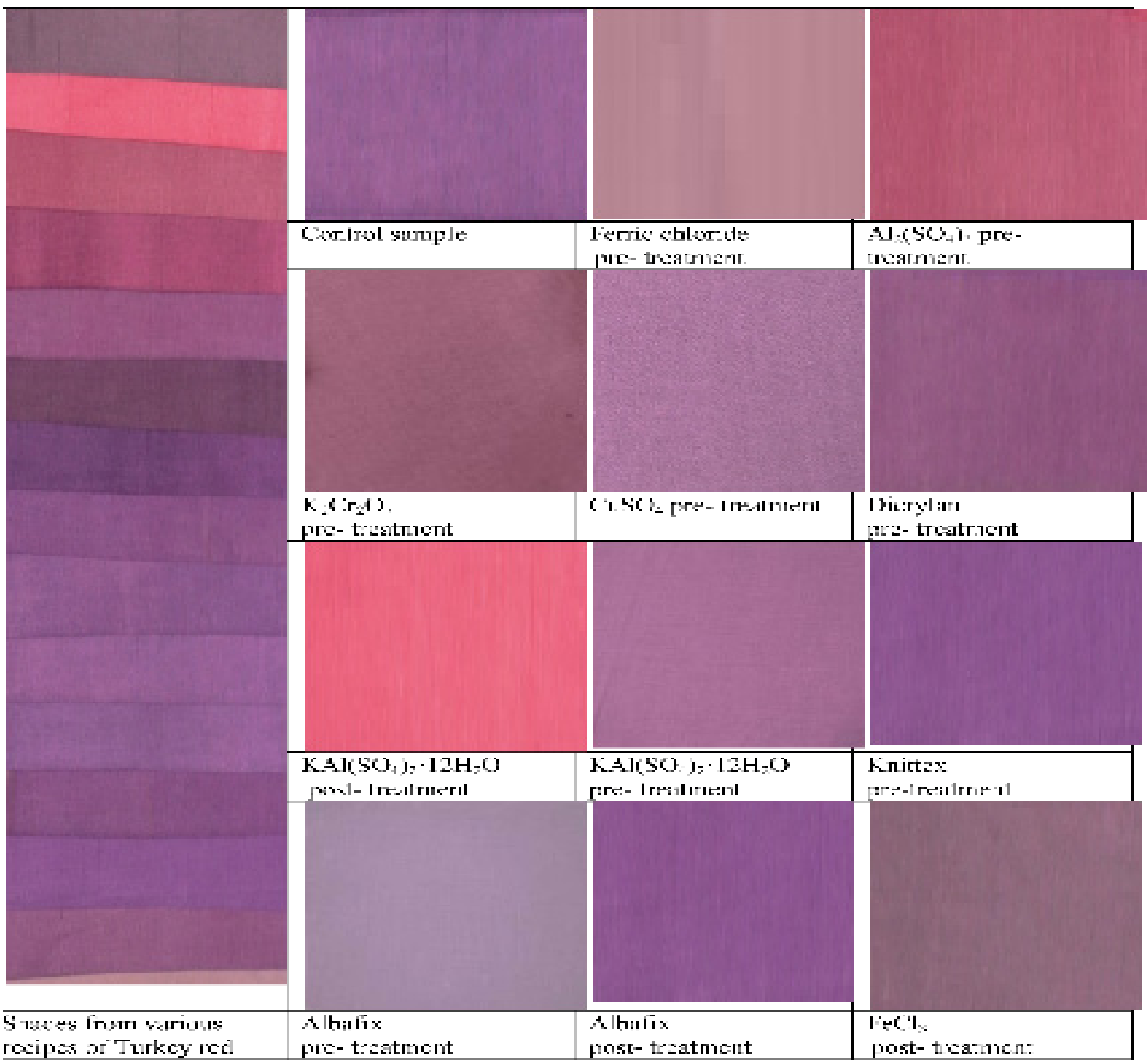

Figure 2 Shades produced by cotton samples dyed with natural extracts of Turkey red natural dye under different conditions.

Reddish purple samples were yielded by treatments of posttreatment of copper sulphate (dark shade), pre- treatment with hydrated potassium aluminium sulfate (medium reddish purple) and pre- treatment by copper sulphate (light shade). The effect of mordants and natural dyes on the shade and colour fastness has been widely reported. One of the advantages of natural dyeing is that the same dye yielding plant species produce variety of colours by means of various mordants. While discussing the effect of mordant on colour, Gupta et al. ${ }^{21}$ have reported that a range of colours from purpurin by the use of various mordants was very wide. They obtained brownish red colour by the use of copper sulphate and deep red with $\mathrm{KAl}\left(\mathrm{SO}_{4}\right)_{2} \cdot 12 \mathrm{H}_{2} \mathrm{O}$ and other mordants. The present results support their findings as alum produced red (flame red) colour with the use of madder dye on cotton and the post- padding of copper sulphate as mordant yielded brown red. ${ }^{22}$

\section{Conclusion}

The role of mordants in creating variety of shade/ colours on cotton fabric from the same dye, similar procedure as well as identical dyeing conditions was evident from both the natural dyes utilized in the current study. Madder and Turkey red exhibited wide range of red to violet shades. Each mordant yielded its individual limited but remarkable range of colour. UV absorbers and cross-linkers utilized in this study did not affect the intensity of shade. Shades of samples dyed with these treatments were similar to the shade of control sample.

\section{Acknowledgments}

None.

\section{Conflicts of interest}

The authors declare that they have no competing interests.

\section{References}

1. Ke G, Yu W, Xu W. Color evaluation of wool fabric dyed with Rhizoma coptidis extract. Journal of Applied Polymer Science. 2006;101(5):33763380

2. Corbman BP. Textiles: Fibres to fabric. 6th ed. McGraw-Hill International editions; 1985:201-203 
3. Bechtold T, Mussak R. Handbook of natural colorants. West Sussex, England: John Wiley \& Sons; 2009:315-338. ISBN: 978-0-470-51199-2.

4. Ratnapandian S, Fergusson SMA, Wang L. Application of Acacia natural dyes on cotton by pad dyeing. Fibers and Polymers. 2012;13(2):206-211.

5. Trotman ER. Dyeing and Chemical Technology of Textile Fibres. 6th ed. Bucks, England: Charles Griffin Company Ltd; 1984.

6. Yusuf M, Shahid M, Khan IM, et al. Dyeing studies with henna and madder: A research on effect of tin (II) chloride mordant. Journal of Saudi Chemical Society. 2015;19(1):64-72.

7. Nateri AS. Reusing Waste water of madder natural dye for wool dyeing. Journal of Cleaner Production. 2011;19(6-7):775-781.

8. Deo HT, Paul R. Eco-friendly mordant for natural dyeing of denim. International Dyer. 2003;188:49-52.

9. Mahatma D, Tamari SC. Natural dye-yielding plants and indigenous knowledge on dye preparation in Acronychal Pradesh, Northeast India. Carr Ski. 2005;88:1474-1480.

10. Moiz A, Ahmed MA, Kausar N, et al. Study the effect of metal ion on wool fabric dyeing with tea as natural dye. Journal of Saudi Chemical Society. 2010;14(1):69-76.

11. MacDougall DB. Color in Food, Improving Quality. Woodhead Publishing Ltd, UK: Cambridge; 2002.

12. Ratnapandian S. Application of natural dyes by padding technique on textiles. PhD Dissertation, RMIT University Australian; 2013.

13. Nakpathom M, Somboon B, Narumol N, et al. Natural dyeing of hemp yarns. Bangkok, Thailand: RMUTP International Conference: Textiles and Fashion; 2012.

14. Goodarzian H, Ekrami E. Extraction of dye from madder plant (Rubia tinctorum L.) and dyeing of wool. World Applied Sciences Journal. 2010;9(4):434-436.
15. Derksen GCH. Red, redder, madder: analysis and isolation of anthraquinone from madder roots (Rubia Tinctorum). PhD dissertation, Netherland: Wageningen University; 2001.

16. Kasiri MB, Safapour S. Natural dyes and antimicrobials for green treatment of textiles. Environmental Chemistry Letters. 2013;12(1):1-13.

17. Wanyama PAG, Kiremire BT, Ogwok P, et al. The effect of different mordants on strength and stability of colour produced from selected dyeyielding plants in Uganda. International Archive of Applied Sciences and Technology. 2010;1(2):81-92.

18. Saravanan P, Chandramohan G, Sundaram PS, et al. A study on extraction and application of eco friendly natural dye extracted from leaves of Acalypha indica Linn on silk fabric. International Journal of Textile and Fashion Technology. 2013;5(3):1-8.

19. Zarkogianni E, Mikropoulou E, Varella E, et al. Colour and fastness of natural dyes: revival of traditional dyeing techniques. Coloration Technology. 2010;127(1):18-27.

20. Khattak SP, Rafique S, Hussain T, et al. Optimization of fastness and tensile properties of cotton fabric dyed with natural extracts of Marigold flower (Tagetes erecta) by pad-steam method. Life Science Journal. 2014;11(7s):52-60.

21. Gupta D, Gulrajani M, Kumari S. Light fastness of naturally occurring anthraquinone dyes on nylon. Coloration Technology. 2004;120(5):205212.

22. Khattak SP, Rafique S, Hussain T, et al. Colour Fastness and Tensile Strength of Cotton Fabric Dyed with Natural Extracts of Alkanna tinctoria by Continuous Dyeing Technique. Chem Soc Pak. 2015;37(5):903-909. 